\title{
Relationship between ankle range of motion and Biodex Balance System in females and males
}

\author{
Eun-Sook Sung', Jung-Hyun Kim ${ }^{2 * *}$ \\ 'Department of Sports Rehabilitation, College of Health Welfare, Woosong University, Daejeon, Korea \\ 2Department of Physical Therapy, College of Health Welfare, Woosong University, Daejeon, Korea
}

This study examined whether there are differences between range of motion (ROM) and balance in lower extremities according to gender. $A$ total of 31 male and 28 female students measured plantar flexion (PF), dorsiflexion, inversion (IV), eversion (EV), hip flexion (HF), hip internal rotation (HIR), and hip external rotation (HER) and tested on the Biodex Balance System. ROM of PF and HF were significantly high the female group and ROMs of IV, EV, HIR, and HER were significantly higher the male group than in the female group. Low ROM of PF may be more negative related to overall balance, especially, back balance in males; therefore, it is necessary to assess and plan the training program for PF ROM in male students.

Keywords: Gender identity, Lower extremity, Postural balance, Range of motion

\section{INTRODUCTION}

The balance is very important component to prevent elderly fall and to improve rehabilitation after injury in low extremity. There are various factors for optimal balance, which are sensorimotor, visual acuity, vestibular function, central and peripheral sensor, cerebellar function, muscle strength of both lower extremities, and between male and female (Bok et al., 2013). Most previous studies demonstrated that optimal balance can improve postural control and decrease the injury risk of low extremity (Goldie et al., 1994; McCluskey et al., 1976; Tropp et al., 1985).

Several studies have examined gender differences in balance performance. They reported that male have a worse balance and a greater instability in low extremity than female (Bryant et al., 2005; Era et al., 2002) and another study reported that it exists gender differences in balance performance and there has been a higher incidence of falling in female than in male (Menz et al., 2005; Mika et al., 2012). Moreover, several studies demonstrated that possible explanation for gender differences might be the intrinsic differences of anthropometric characteristics (Taimela et al.,
1990). The ankle joint of range of motion (ROM) is an important part of the human kinetic chain, playing an important role in posture balance and gait (Murray et al., 1985) and it is an intrinsic factor involved in low extremity injury and ankle injury in sports. Other studies reported that lack of dorsiflexion (DF) can be caused by many ankle joint impairments, such as weakness of dorsiflexors, spasticity of plantar flexors, passive stiffness of the plantar flexors, or walking disabilities (Crenna, 1998). Decreasing of ankle joint ROM influences many aspects of function and balance (Bennell and Goldie, 1994). Ankle is focused primarily on plantar flexion (PF) and DF and flexibility and strength of toe plantarflexor muscle strength are significantly associated with posture balance and physical functional ability (Menz et al., 2005). Movement of the DF and PF is necessary to allow optimal force generation and balance strategy execution to decrease fall risk (Studenski et al., 1991). In addition, foot and ankle characteristics, which are plantar flexor strength of toe and of ankle inversion (IV)-eversion (EV) ROM, are important for sway balance and functional ability in elderly people (Spink et al., 2011). Mecagni et al. (2000) reported the ankle IV-EV ROM was also found to be significantly
${ }^{*}$ Corresponding author: Jung-Hyun Kim (iD https://orcid.org/0000-0002-4710-8145 Department of Physical Therapy, College of Health Welfare, Woosong University, 171 Dongdaejeon-ro, Dong-gu, Deajeon 34606, Korea

Tel: +82-42-630-4625, Fax: +82-42-630-4611, E-mail: junghyunkim9144@gmail.com Received: October 26, 2017 / Accepted: January 16, 2018
This is an Open Access article distributed under the terms of the Creative Commons Attribution Non-Commercial License (http://creativecommons.org/licenses/by-nc/4.0/) which permits unrestricted non-commercial use, distribution, and reproduction in any medium, provided the original work is properly cited. 
associated with balance and functional test performance. In order to minimize the fall risk and prevent of ankle injury, it is essential to confirm the differences of balance with low extremity according to ROM between females and males. Murray et al. (1985) described that there are minimal differences of ROM between females and males. However, there is a lack of studies regarding the ROM in low extremity and the difference in males and females. Thus, the purpose of our study was to examine the differences of ankle ROM and balance between healthy female and male students.

\section{MATERIALS AND METHODS}

\section{Subjects}

Thirty-one male and 28 female students completed to participate in this study. Subjects were moderately trained students. They had previously been screened and diagnosed by an orthopedic surgeon. All subjects did not present neurological signs of pathological importance in the clinical examination and they have previous experience with balance training on the Biodex Balance System (BBS). Before of the study, all participants were informed about the purpose, procedures and possible risks of the study and written informed consent was obtained from each participant.

\section{Active ankle ROM}

Subjects lay supine with outstretched legs on an examination table without any pad, cushion or pillow underneath for PF, DF, IV, EV, hip flexion (HF), hip internal rotation (HIR), and hip external rotation (HER). The testing position of ankle started $90^{\circ}$ for ankle joint and stated supine position with anatomical position for HF, HIR, and HER. The active ROM, like self-stretching, was calculated by the summation of degrees of PF, DF, HF, HIR, and HER. The greater degree means the higher flexibility.

\section{Biodex Balance Test}

To assess balance of postural stability, limits of stability and fall risk the subjects received postural stability test with the BBS (Biodex Medical Systems, Shirley, NY, USA). Postural stability test were measured 20-sec trials with 1-min intervals between them and simulated particular movement patterns by fixed platform. This platform stability was set to moderately stable and in each session, the subjects sway is used to assess the postural stability. The BBS software calculated a subject's functional balance ability of the anterior/posterior index, medial/lateral index, and overall stability index during a given task. These indices were cal- culated using the degree of oscillation of the platform and low values showed that the subjects had good posture stability. The average of three tests was considered the subject index. Limits of stability for static and dynamic standing balance can be showed that posture stability can be achieved as maximum angle from vertical without losing balance. The test includes 14 items and those results of integration with sensory and motor control aspects for posture balance can play an important role in daily life. For the fall risk test, the platform is unstable and the subject's test was measured with fall risk test protocol. According to the BBS software, 2 trials of $20 \mathrm{sec}$ each at a stability level of 8 were measured with 10-sec rest between set. Fluctuations around the zero point, established prior to testing when the platform is stable, are presented as the findings of this test (Ibrahim et al., 2016).

\section{Statistical analysis}

Data processing and analysis was used IBM SPSS Statistics ver. 22.0 (IBM Co., Armonk, NY, USA). Descriptive analysis was used mean and standard deviation for general characteristics. Independent $t$-test was used to determine the difference ROM in lower extremities and balance in male and female students. All data was presented using mean values with standard deviation. The statistical significance level was less than 0.05 in $P$-value.

\section{RESULTS}

Thirty-one males (age, $20.63 \pm 1.67$ years; height, 176.19 \pm $6.31 \mathrm{~cm}$; weight, $77.33 \pm 11.97 \mathrm{~kg}$; body mass index [BMI], $24.24 \pm 5.02 \mathrm{~kg} / \mathrm{m}^{2}$ ) and 28 female students (age, $20.31 \pm 1.31$ years; height, $161.90 \pm 6.17 \mathrm{~cm}$; weight, $62.40 \pm 13.20 \mathrm{~kg}$; BMI, $23.88 \pm 5.46 \mathrm{~kg} / \mathrm{m}^{2}$ ) were participated in this study (Table 1 ). This study showed differences ROM of low extremities (ankle and hip ROM) according to gender. ROM of PF and HF were significantly higher female group (right, $54.10^{\circ} \pm 9.36^{\circ}$; left, $56.13^{\circ} \pm$ $10.73^{\circ}$ in PF and right, $121.91^{\circ} \pm 8.00^{\circ}$; left, $121.93^{\circ} \pm 8.66^{\circ}$ in HF) than male group (right, $49.30^{\circ} \pm 8.43^{\circ}$; left, $48.87^{\circ} \pm 7.49^{\circ}$ in

Table 1. General characteristics of subjects

\begin{tabular}{lcc}
\hline Characteristic & Male $(\mathrm{n}=31)$ & Female $(\mathrm{n}=28)$ \\
\hline Age $(\mathrm{yr})$ & $20.63 \pm 1.67$ & $20.31 \pm 1.31$ \\
Height $(\mathrm{cm})$ & $176.19 \pm 6.31$ & $161.90 \pm 6.17$ \\
Weight $(\mathrm{kg})$ & $77.33 \pm 11.97$ & $62.40 \pm 13.20$ \\
Body mass index $\left(\mathrm{kg} / \mathrm{m}^{2}\right)$ & $24.24 \pm 5.02$ & $23.88 \pm 5.46$ \\
Dominant leg, right:left & $29: 2$ & 26.2 \\
\hline
\end{tabular}

Values are presented as mean \pm standard deviation or number. 
Table 2. Differences of range of motion of lower extremities in male and female students $(n=59)$

\begin{tabular}{lccc}
\hline Characteristic & Male $(n=31)$ & Female $(n=28)$ & $P$-value \\
\hline $\begin{array}{l}\text { Dorsiflexion } \\
\text { Right }\end{array}$ & $17.71 \pm 4.97$ & $17.39 \pm 5.68$ & 0.82 \\
Left & $17.32 \pm 4.89$ & $17.37 \pm 4.72$ & 0.97 \\
$\begin{array}{l}\text { Plantarflexion } \\
\text { Right }\end{array}$ & $49.30 \pm 8.43$ & $54.10 \pm 9.36$ & $0.04^{*}$ \\
$\quad$ Left & $48.87 \pm 7.49$ & $56.13 \pm 10.73$ & $0.004^{*}$ \\
Inversion & & & \\
$\quad$ Right & $37.73 \pm 10.54$ & $31.54 \pm 8.01$ & $0.02^{*}$ \\
Left & $38.54 \pm 10.12$ & $33.30 \pm 6.95$ & $0.03^{*}$ \\
Eversion & & & \\
Right & $26.21 \pm 5.92$ & $20.10 \pm 5.98$ & $0.001^{*}$ \\
Left & $24.84 \pm 6.87$ & $20.41 \pm 7.54$ & $0.02^{*}$ \\
Hip flexion & & & \\
$\quad$ Right & $117.38 \pm 7.49$ & $121.91 \pm 8.00$ & $0.03^{*}$ \\
Left & $117.03 \pm 8.12$ & $121.93 \pm 8.66$ & $0.03^{*}$ \\
Hip internal rotation & & & \\
$\quad$ Right & $39.13 \pm 10.98$ & $32.86 \pm 11.69$ & $0.04^{*}$ \\
Left & $40.05 \pm 12.08$ & $32.58 \pm 11.95$ & $0.02^{*}$ \\
Hip external rotation & & & \\
Right & $52.44 \pm 10.65$ & $46.15 \pm 9.35$ & $0.02^{*}$ \\
Left & $52.24 \pm 9.26$ & $47.06 \pm 10.61$ & $0.05^{*}$ \\
\hline
\end{tabular}

Values are presented as mean \pm standard deviation $\left({ }^{\circ}\right.$.

${ }^{*} P<0.05$, statistically significant.

PF and right, $117.38^{\circ} \pm 7.49^{\circ}$; left, $117.03^{\circ} \pm 8.12^{\circ}$ in HF) $(P<$ $0.05)$. ROM of IV, EV, HIR, and HER were significantly higher male group (right, $37.73^{\circ} \pm 10.54^{\circ}$; left, $38.54^{\circ} \pm 10.12^{\circ}$ in IV; right, $26.21^{\circ} \pm 5.92^{\circ}$; left, $24.84^{\circ} \pm 6.87^{\circ}$ in EV; right, $39.13^{\circ} \pm$ $10.98^{\circ}$; left, $40.05^{\circ} \pm 12.08^{\circ}$ in HIR; right, $52.44^{\circ} \pm 10.65^{\circ}$; left, $52.24^{\circ} \pm 9.26^{\circ}$ in HER) than female group (right, $31.54^{\circ} \pm 8.01^{\circ}$; left, $33.30^{\circ} \pm 6.95^{\circ}$ in IV; right, $20.10^{\circ} \pm 5.98^{\circ}$; left, $20.41^{\circ} \pm 7.54^{\circ}$ in $\mathrm{EV}$; right, $32.86^{\circ} \pm 11.69^{\circ}$; left, $32.58^{\circ} \pm 11.95^{\circ}$ in HIR; right, $46.15^{\circ} \pm 9.35^{\circ}$; left, $47.06^{\circ} \pm 10.61^{\circ}$ in HER $)(P<0.05)$. However, there is no significant difference of DF was founded between male and female students (Table 2). Moreover, female group had a significantly better limits of stability than male group in back ward (male, 71.35 \pm 16.96 ; female, 60.68 \pm 20.11 ) and backward-left (male, 61.61 \pm 12.98 ; female, $47.68 \pm 13.67$ ), back ward-right (male, 61.90 \pm 17.70 ; female, $49.93 \pm 13.98)(P<0.05)$ (Table 3). Furthermore, female group had a significantly better of visual stability during eye close (male, 1.38 \pm 0.77 ; female, $0.99 \pm 0.31$ ) and of fall risk (male, $1.73 \pm 0.95$; female, $0.77 \pm 0.29$ ) than male group $(P<0.05)$ (Table 3).
Table 3. Differences of global balance parameters in male and female students $(n=59)$

\begin{tabular}{lccc}
\hline Characteristic & Male $(\mathrm{n}=31)$ & Female $(\mathrm{n}=28)$ & $P$-value \\
\hline $\begin{array}{l}\text { Postural stability } \\
\text { Anterior-posterior }\end{array}$ & $0.27 \pm 0.09$ & $0.26 \pm 0.08$ & 0.45 \\
$\quad$ Medal-lateral & $0.20 \pm 0.13$ & $0.18 \pm 0.06$ & 0.51 \\
Limits of stability & & & \\
Forward & $55.35 \pm 19.19$ & $57.18 \pm 17.46$ & 0.71 \\
Backward & $71.35 \pm 16.96$ & $60.68 \pm 20.11$ & $0.03^{*}$ \\
Left & $65.19 \pm 15.65$ & $59.54 \pm 20.22$ & 0.23 \\
Right & $65.00 \pm 17.38$ & $60.71 \pm 15.53$ & 0.32 \\
Forward-left & $57.65 \pm 15.87$ & $55.79 \pm 17.94$ & 0.67 \\
Forward-right & $59.71 \pm 16.50$ & $52.07 \pm 16.33$ & 0.08 \\
Backward-left & $61.61 \pm 12.98$ & $47.68 \pm 13.67$ & $0.001^{*}$ \\
Backward-right & $61.90 \pm 17.70$ & $49.93 \pm 13.98$ & $0.006^{*}$ \\
Visual stability & & & \\
Eye open & $0.43 \pm 0.14$ & $0.45 \pm 0.12$ & 0.57 \\
Eye close & $1.38 \pm 0.77$ & $0.99 \pm 0.31$ & $0.02^{*}$ \\
Fall risk & $1.73 \pm 0.95$ & $0.77 \pm 0.29$ & $0.001^{*}$ \\
\hline
\end{tabular}

Values are presented as mean \pm standard deviation.

${ }^{*} P<0.05$, statistically significant.

\section{DISCUSSION}

The primary aim of this study was to investigate the relationship between ROM in lower extremities and postural-, limits-, visual-stability and fall risk with BBS in female and male students. To the best of our knowledge, the present study is the first to evaluate the relationship between postural balance and ROM of lower extremities in female and male students. The BBS is a reliable and reproducible method for evaluating postural-, limits-, and visual-stability and fall risk from the posture's center of mass that can be made while maintaining postural stability (Cachupe et al., 2001). Several studies have examined gender differences in balance performance. They reported that males have a worse balance and a greater instability in low extremity than females (Bryant et al., 2005; Crenna, 1998; Denegar et al., 2002; Era et al., 2002). Furthermore, they also reported that female have higher incidence of falling risk than male (Menz et al., 2005; Mika et al., 2012). Moreover, several studies demonstrated that possible explanation for gender differences might be the intrinsic differences of anthropometric characteristics. Kejonen et al. (2003) demonstrated that body anthropometric characteristics influence the variations of body-balancing movements in balance and body mass are related to postural balance between obese and nonobese subjects (McGraw et al., 2000). However, few studies have reported gender differences with ROM of lower extremity and balance. 
Therefore, in the present study, we found that females have a better balance and also a better ROM of PF and HF than males. These results are consistent with Spink et al. (2011) who reported that foot and ankle characteristics, which are plantar flexor strength of toe and of ankle IV-EV ROM, are important of sway balance and walking functional ability in elderly people (Spink et al., 2011). Congruently, in Mecagni et al. (2000) the ankle IV-EV ROM was also found to be significantly associated with balance and physical functional performance test. Our results show that low IV and EV ROM have a negative influence on balance in males. Specifically, one of various ROMs, PF, plays an important role in supporting weight of body and providing stability at the ankle and feet for standing and gait, whereas dorsiflexor muscle against gravity during the swing phase of gait clears the feet from the floor and those authors carefully suggested that static balance may be related to more plantarflexor strength than dorsiflexor (Bok et al., 2013). Menz et al. (2005) also reported ankle flexibility and strength of toe plantarflexor muscle strength to be significantly associated with balance and functional ability. This gender difference of PF ROM is supported by Mika et al. (2012) who found that that high-heeled shoes increased knee flexion and decreased ankle EV. Consistently with our results on PF that positively influence the overall balance, this finding provides further evidence that females have a higher ROM of $\mathrm{EV}$ and $\mathrm{HF}$ than males.

In conclusion, this study demonstrates that the gender difference of ankle ROM and balance. Specifically, our results show that females have a better ankle ROM of PF than males and males have a higher ROM of IV, EV, HIR, and HER than females. Low ROM of PF may be more negative related to overall balance, especially, back balance in males; therefore, it is necessary to assess and plan the training program for PF ROM in males. Further research is needed for intervention programs to improve the PF flexibility in males; furthermore, IV, EV, HIR, and HER flexibility in females would be beneficial for improving balance and prevention of falls.

\section{CONFLICT OF INTEREST}

No potential conflict of interest relevant to this article was reported.

\section{ACKNOWLEDGMENTS}

The authors thank all the participants which, without their help, we were not able to conduct the study.

\section{REFERENCES}

Bennell KL, Goldie PA. The differential effects of external ankle support on postural control. J Orthop Sports Phys Ther 1994;20:287-295.

Bok SK, Lee TH, Lee SS. The effects of changes of ankle strength and range of motion according to aging on balance. Ann Rehabil Med 2013;37:10-16.

Bryant EC, Trew ME, Bruce AM, Kuisma RM, Smith AW. Gender differences in balance performance at the time of retirement. Clin Biomech (Bristol, Avon) 2005;20:330-335.

Cachupe WJ, Shifflett B, Kahanov L, Wughalter EH. Reliability of biodex balance system measures. Meas Phys Educ Exerc Sci 2001;5:97-108.

Crenna P. Spasticity and 'spastic' gait in children with cerebral palsy. Neurosci Biobehav Rev 1998;22:571-578.

Denegar CR, Hertel J, Fonseca J. The effect of lateral ankle sprain on DF range of motion, posterior talar glide, and joint laxity. J Orthop Sports Phys Ther 2002;32:166-173.

Era P, Heikkinen E, Gause-Nilsson I, Schroll M. Postural balance in elderly people: changes over a five-year follow-up and its predictive value for survival. Aging Clin Exp Res 2002;14(3 Suppl):37-46.

Goldie PA, Evans OM, Bach TM. Postural control following inversion injuries of the ankle. Arch Phys Med Rehabil 1994;75:969-975.

Ibrahim MS, Mattar AG, Elhafez SM. Efficacy of virtual reality-based balance training versus the Biodex balance system training on the body balance of adults. J Phys Ther Sci 2016;28:20-26.

Kejonen P, Kauranen K, Vanharanta H. The relationship between anthropometric factors and body-balancing movements in postural balance. Arch Phys Med Rehabil 2003;84:17-22.

McCluskey GM, Blackburn TA Jr, Lewis T. Prevention of ankle sprains. Am J Sports Med 1976;4:151-157.

McGraw B, McClenaghan BA, Williams HG, Dickerson J, Ward DS. Gait and postural stability in obese and nonobese prepubertal boys. Arch Phys Med Rehabil 2000;81:484-489.

Mecagni C, Smith JP, Roberts KE, O'Sullivan SB. Balance and ankle range of motion in community-dwelling women aged 64 to 87 years: a correlational study. Phys Ther 2000;80:1004-1011.

Menz HB, Morris ME, Lord SR. Foot and ankle characteristics associated with impaired balance and functional ability in older people. J Gerontol A Biol Sci Med Sci 2005;60:1546-1552.

Mika A, Oleksy Ł, Mika P, Marchewka A, Clark BC. The influence of heel height on lower extremity kinematics and leg muscle activity during gait in young and middle-aged women. Gait Posture 2012;35:677-680.

Murray MP, Gore DR, Gardner GM, Mollinger LA. Shoulder motion and muscle strength of normal men and women in two age groups. Clin Orthop Relat Res 1985;(192):268-273. 
Spink MJ, Fotoohabadi MR, Wee E, Hill KD, Lord SR, Menz HB. Foot and ankle strength, range of motion, posture, and deformity are associated with balance and functional ability in older adults. Arch Phys Med Rehabil 2011;92:68-75.

Studenski S, Duncan PW, Chandler J. Postural responses and effector factors in persons with unexplained falls: results and methodologic is- sues. J Am Geriatr Soc 1991;39:229-234.

Taimela S, Kujala UM, Osterman K. Intrinsic risk factors and athletic injuries. Sports Med 1990;9:205-215.

Tropp H, Odenrick P, Gillquist J. Stabilometry recordings in functional and mechanical instability of the ankle joint. Int J Sports Med 1985;6: 180-182. 